\title{
Refractory Stress Urinary Incontinence
}

\author{
Sara M. Lenherr and Arthur P. Mourtzinos \\ Lahey Clinic Medical Center, Department of Urology \\ USA
}

\section{Introduction}

Treatment of stress urinary incontinence (SUI) caused by urethral hypermobility or intrinsic sphincter deficiency with urethral sling procedures may yield up to a $80-90 \%$ success rate depending on the definition of success. (Nilsson et al. 2001; Liapis et al. 2002; Rodriguez \& Raz 2003; Nilsson et al. 2004; Ward \& Hilton 2004) In a minority of patients, however, there is persistence or worse incontinence after surgical therapy. In the general population, risk factors for midurethral sling (MUS) failure are BMI $>25$, mixed incontinence, intrinsic sphincter deficiency, diabetes mellitus, advanced patient age $>75$ years old and prior continence surgery. (Cammu et al. 2009; Stav et al. 2010) Potential surgery related reasons for failure include improper adjustment of the sling or misplacement of the suburethral tape. Female patients with urethral incompetence and severe incontinence due to multiple failed surgeries, neurologic injury, or congenital anomalies represent a unique surgical challenge.

Patients with neurologic conditions have sacral arc lesions with paralysis of the skeletal musculature and an open urethra. All other patients who have failed multiple sling and anti-incontinence procedures may have severe symptoms of SUI and an open urethra with a low valsalva leak point pressure. These patients often have an incompetent, difficult to compress, urethra likely due to a combination of urethral denervation, and violation of the periurethral fascia, as well as their underlying risk factors for SUI. (Bump \& Norton 1998) These patients have been shown to have low chances of cure after repeat anti-incontinence surgery and be more likely to suffer from complications including retention, osteomyelitis, and pelvic abscess. (Petrou \& Frank 2001)

In the recurrent or refractory stress urinary incontinence female patient, a routine sling procedure providing only posterior support will not typically yield an appropriate response. Management options include repeat placement of a "tight" pubovaginal sling or replacement of a different type of sling, a spiral sling, periurethral bulking agents, adjustable continence therapy (ACT) device and the artificial urinary sphincter (AUS) prior to bladder neck closure with continent urinary diversion. This manuscript will review the evaluation and management options for recurrent stress urinary incontinence in this challenging population.

\section{Evaluation}

There are a significant number of patients in the United States that undergo successful sling placement for SUI, however a minority will present with persistent or recurrent 
incontinence. Recurrent stress urinary incontinence after urethral sling surgery (transvaginal tape and transobturator tape) and common complications such as urinary tract infection and de novo urge urinary incontinence need to be fully evaluated. It is also important when determining the etiology of surgical failure to identify whether the patient has refractory SUI by determining whether there was any period of cure or improvement. Recurrent stress urinary incontinence warrants at a minimum: complete history and physical examination and urinalysis. Most physicians would advocate urodynamic testing in cases of failed previous surgery for incontinence. (Houwert et al. 2010; Walsh \& Moore 2010) Cystoscopic evaluation is easy to perform in the clinic and should be utilized to determine if there is evidence of sling erosion or misplacement. Ultimately, the determination must be made whether this leakage is due to bladder or outlet dysfunction.

If there is evidence of flank or pelvic pain, a retroperitoneal ultrasound with evaluation of the bladder is necessary to evaluation for obstruction and or injury to the ureteral orifices. Urodynamics with or without fluoroscopy is useful to further characterize the physiology of the bladder. While there is no published data regarding routine use, most practices use routine urodynamic evaluation of failed anti-incontinence patients prior to a repeat procedure. (Rutman et al. 2006; Rodriguez et al. 2010; Walsh \& Moore 2010)

Some urologists routinely use dynamic T2-weighted MRI to look at the anatomic defects seen in pelvic floor dysfunction. A vaginal examination might demonstrate a change in the patient's pelvic floor anatomy, such as evidence of prolapse. Many researchers have used dynamic MRI to evaluate the female pelvis and delineate the possible components of pelvic floor dysfunction. This requires experience using this modality and a radiologist that can interpret the test in a useful way. In the cost-saving climate of health care today, dynamic T2 MRI can likely only be used in the setting of severe refractory incontinence or neurologic conditions.

\section{Nonsurgical management}

There is a paucity of literature for the nonsurgical management of recurrent SUI following prior surgical repair. Most treatments are based on primary SUI studies, namely pelvic floor muscle training, weight loss, incontinence pessary and medications. These options have been systematically reviewed elsewhere. (Shamliyan et al. 2008)

\section{Periurethral bulking agents}

While the majority of patients that have failed surgical repair for SUI will opt for a more aggressive intervention, periurethral bulking agents offer a potential adjunct for the insufficient sling, especially if the patient or surgeon are hesitant to be more invasive given the history of prior urethral surgery. Periurethral bulking agents include biodegradable and nonbiodegradable agents that are injected endoscopically in the perurethral tissue to presumably further coapt the urethral mucosa. While the availability of these agents has recently changed, the primary injectable bulking agents in the United States include Contigen (Bard Inc., Murry Hill, NJ) which has recently been discontinued, Durasphere (Coloplast Inc, Minneapolis, MN), Macroplastique (Uroplasty Inc, Minneapolis, MN) and Coaptite (Bioform Inc., Franksville, WI). 
Investigators have reported the use of periurethral bulking agents after failed sling procedures for SUI, but no randomized studies have been reported. However, a recent report looking at intermediate follow up has reported some success. Macroplastique and Durasphere were used as periurethral bulking agents in 23 women following a failed midurethral sling procedure. (Lee et al. 2010) Macroplastique was used in 21 patients and Durasphere was used in 2 patients with a median interval between sling placement and periurethral bulking agent injection of 12 months (range 3-65). With intermediate follow up at a median of 10 months (range 6-34 months), 8 of 23 patients (35\%) of all patients reported "cure" whereas $92 \%$ reported they had benefited from the procedure. Notably, $77 \%$ of the women reported satisfaction from the procedure, perhaps noting the relative simplicity and ease of placement.

\section{Revision urethral sling surgery}

The literature is maturing with regard to the appropriate choice for a repeat sling following midurethral sling for SUI. Stav and colleagues reviewed the cases of 1225 retrospectively identified women who underwent either a retropubic or transobturator sling. $91 \%$ of these patients completed a telephone interview questionnaire. (Stav et al. 2010) The majority of these women had a retropubic sling as opposed to a transobturator sling. Mean follow up was 50 months. Their re-operation rate for failure was $14 \%$. Repeat retropubic sling placement was significantly more successful than utilizing a transobturator approach $(71 \%$ vs $48 \%, \mathrm{p}=0.04)$. Repeat slings were placed without removal of the previous sling. Most surgeons will opt to use a retropubic sling for recurrent incontinence and rather than a transobturator sling because of the greater urethral tension generated. Management options also include repeat placement of a "tight" pubovaginal sling with the intent of putting the patient in urinary retention. This can be done utilizing autologous fascia as well.

\section{Adjustable Continence Therapy (ACT) system}

The efficacy, safety \& technical feasibility of the ACT was initially reported in 2009 as a novel device for the treatment of recurrent female SUI. (Aboseif et al. 2009) The device is intended to be a minimally invasive implantable device that provides support at the urethrovesical junction and enhances urethral coaptation. Its unique advantage is that it is also adjustable allowing for further optimization of the device post-operatively.

Placement of the ACT device is via bilateral small incisions between the labia majora and minora at the level of the urethral meatus with a specially designed trocar. Fluoroscopic and digital guidance is used to identify a point just distal to the urethrovesical junction where the balloons are placed. The balloons are then inflated with 1-1.5 $\mathrm{mL}$ of isotonic contrast solution. The subcutaneous inflation ports are then placed in a pocket in a superior ventral portion of each labia majora and the skin is closed with subcuticular absorbable suture. (Aboseif et al. 2009; Kocjancic et al. 2010)

The initial experience with the ACT system showed a complication rate of $24.4 \%$ (38 of 156 patients). Complications included port erosion, urinary retention, balloon erosion or migration and worsening incontinence. 18.3\% (28 of 153) of patients underwent explantation within the first year, however $50 \%$ of explanted cases then underwent replacement. Since the development of the device, improvement in the technical related learning curve has led to reduced rates of complications. 
At a mean follow-up of 72 months (range 12-84), 68\% of patients $(n=29)$ reported themselves dry. (Kocjancic et al. 2010) All of these patients had at least one prior pelvic surgery for SUI. The researchers reported 12 month urodynamic data $(n=30$ patients) which showed a statistically significant increase in VLPP from a mean baseline of $51.06 \pm 24.38$ to $86.0 \pm 21.44$ $\mathrm{cm} \mathrm{H}_{2} \mathrm{O}(\mathrm{p}<0.01)$. Complications requiring device removal developed in $21.1 \%$ of patients.

Most recently, Aboseif and colleagues presented a series of 89 patients with the ACT device. (Aboseif et al. 2011) They reported that $47 \%$ of the patients were dry at 1 year and $92 \%$ overall were subjectively improved. Pads per day and incontinence episodes were significantly improved, in addition to outcomes on standardized questionnaires. Their complication rate was similar to previously published studies with an explant rate of $21.7 \%$. Proponents of the ACT device, that are proficient in placement and adjustment, report it is effective, simple and safe.

\section{Artificial urinary sphincter}

The AUS in the female population differs from the suburethral sling in that it does not provide a backboard or urethral support, but rather it attempts to mimic the sphincter mechanism of the urethra with circumferential compression. (Light \& Scott 1985) The initial use of the AUS in women with incontinence was described in 1985 (Light \& Scott 1985) and has since been well documented in the literature. (Vayleux et al. 2011)

Costa and colleagues evaluated the efficacy of the AMS 800 AUS in women with Type III incontinence and a negative Marshall test. (Costa et al. 2001) They described a modified surgical procedure through an abdominal approach. Of the 190 patients with working devices, continence was achieved in $88.7 \%$ and $81.8 \%$ of those with non-neurogenic and neurogenic bladders, respectively at a mean follow-up of 3.9 years. 51 patients had perioperative complications and a high percentage of patients had not undergone prior surgical therapy. Thomas and associates reported 12 year follow-up in 68 patients who underwent an AUS. (Thomas et al. 2002) Despite an $81 \%$ continence rate, $46 \%$ required removal or replacement for erosion or infection. They concluded by recommending an AUS in patients with SUI after failure of one anti-stress incontinence operation and rather than as a last resort. More recent series reports demonstrate the safety, efficacy and complication rates associated with female AUS implantation. (Chung et al. 2010; Vayleux et al. 2011) Importantly, while there is a high proportion of patients that continue to use the AUS after implantation, about $50 \%$ of them have required revision or replacement, usually within the first several years of implantation. Continence rate in these two studies indicates $65-70 \%$ for no pads and $73.5-83 \%$ for 0 to 1 pad per day. Satisfaction rates were high with a majority of patients reporting they would undergo AUS placement again if necessary. Additional modifications such as insertion of an AUS laparoscopically (Roupret et al. 2010) or with a large cuff (Revaux et al. 2010) have been proposed, however long-term data is lacking at this time.

\section{Spiral sling procedure}

A newer technique initially described by Raz and colleagues is a transvaginal sling procedure in adult women that encircles the urethra providing circumferential coaptation. The spiral sling is a salvage procedure for a small, yet severe group of female patients with a totally incompetent urethra. The procedure was initially described in patients with congenital or 
neurological diseases. (Rutman et al. 2006) It has more recently been described in patients with multiple failed surgeries for SUI. (Mourtzinos et al. 2008) The procedural details of the spiral sling are not widely published and will therefore be reviewed here in detail.

Notable surgical steps different from other suburethral slings are as follows: Two parallel distal oblique incisions are made in the anterior vaginal wall. The retropubic space is entered and a complete urethrolysis is performed by detaching the urethropelvic ligaments from the arcus tendineous fascia pelvis and freeing all retropubic adhesions. The urethral dissection is started in the mid-urethral area just proximal to the pubo-urethral ligaments and carried proximally to free the rest of the urethra and the bladder neck. Then a suburethral tunnel is created in the anterior vaginal wall $1.5 \mathrm{~cm}$ from the urethral meatus. Polypropylene mesh measuring approximately 1 X $15 \mathrm{~cm}$ is passed dorsally, between the urethra and the pubis. The ends of the mesh are crossed ventrally through the previously made vaginal tunnel. This maneuver creates a complete circle of mesh around the urethra. A suprapubic puncture is made just above the symphysis and a double-pronged needle (Cook Urological, Inc., Spencer, IN) is passed under finger control through the fascia and retropubic space to the vaginal incision. The previously placed 0-polyglactin sutures from the polypropylene mesh are transferred to the suprapubic incision. This is repeated on the contralateral side and the sutures are tied without tension.

Between August 1999 and October 2004, 47 patients underwent placement of a spiral sling. (Rutman et al. 2006) This initial patient population was initially selected because of congenital or neurologic diseases, however, the technique was later expanded to include those patients with multiple failed surgeries for SUI and an incompetent lead pipe urethra. Of the 47 patients, seven were lost to follow-up. The mean age of the remaining 40 patients was 59.0 years (23-86). This represented a complex cohort of patients with $98 \%$ having failed a prior anti-incontinence surgery. The patients had undergone a mean of 2.6 previous antiincontinence surgeries and used an average of 6 pads per day. There were two patients who had previous augmentation cystoplasty and were performing self-intermittent catheterization but had significant SUI between catheterizations. All patients were considered candidates for urethral closure and continent diversion as a salvage procedure.

In this group of 40 patients, the average follow-up was 12 months (6-37). There were no intraoperative complications. The de-novo urge incontinence rate was $7.4 \%$. Of the 27 patients with preoperative urge incontinence (UI), 9 (33\%) had resolution of their symptoms with the procedure. One of the patients had persistent refractory UI and subsequently underwent a sacral neuromodulation procedure. No patient experienced de novo retention after the spiral sling. The four patients who were performing self-intermittent catheterization pre-operatively continued to do so after the procedure. There were no urethral or vaginal erosions. The mean number of pads decreased from 6.0 preoperatively to 0.9 postoperatively $(\mathrm{P}<0.005)$. $78 \%$ of patients reported improvements of $90 \%$ or greater. Patients reported a mean improvement of symptoms of $87 \%$ after surgery. Ultimately, three patients underwent bladder neck closure and continent augmentation and were considered failures.

More recently, the spiral sling technique was described in 46 patients with multiple failed surgeries for SUI excluding patients with neurologic or congenital anomalies. (Mourtzinos, et al. 2008) The mean age of the study population was 62 years and the mean follow-up was 15 months (6 to 45 months). All patients had failed a prior anti-incontinence surgery. There were no intraoperative complications and no cases of permanent urinary retention postoperatively 
requiring transvaginal urethrolysis. On patient driven subjective assessment, $49 \%$ of patients reported never experiencing SUI, and $72 \%$ experienced no or rare episodes of SUI. Overall patients reported a mean improvement of $84 \%$ with a decrease in daily pads from 5.5 to 1.0 . Most patients were highly satisfied with their urinary symptoms after surgery (mean QoL of 1.4). In addition, there was no statistically significant difference between pre and postoperative symptoms of incomplete bladder emptying $(\mathrm{P}>0.05)$.

A review of the literature for alternatives to bladder neck closure revealed no existing circumferential sling procedure in the adult population. Mingin and colleagues described a transabdominal technique of a urethral sling using rectus muscle wrapped around the urethra for pediatric patients with congenital urethral incompetence. (Mingin et al. 2002) Of the 37 patients reported, $92 \%$ remained dry between catheterizations. The pediatric population is unlike this population since these patients had roughly three anti-incontinence surgeries with subsequent scarring and more difficult coaptation. The mechanism of cure of the transvaginal spiral sling is not completely understood. It likely supports the midurethral segment while preventing urethral descent and improving pressure transmission to the urethra. In addition, unlike a routine sling procedure, the spiral sling also provides circumferential coaptation to the urethra at the time of increases in intrabdominal pressure.

Raz and colleagues concluded that the spiral sling is an effective salvage transvaginal procedure that may be considered for a small subset of female patients with non-functional urethras as a last resort prior to urethral closure procedures. This includes patients with urethral incompetence caused by neurologic disease, congenital anomalies or iatrogenic injury from multiple failed anti-incontinence surgeries. The most comparable surgical alternative is the AUS which requires manual dexterity to operate the device and a more extensive dissection to implant all components. The initial outcomes look promising but longer follow-up will better define its role in refractory female incontinence and demonstrate the durability of the spiral sling.

\section{New technologies}

Efficacy, safety \& technical feasibility of intrasphincteric injections of autologous muscle derived stem cells have been shown by several groups in both animal models and humans. (Mitterberger et al. 2008; Sebe et al. 2011) In the human studies, myoblasts and fibroblasts were obtained from muscle biopsies of the patient. Cells are then grown in a culture facility to yield more myoblasts. After amplification, the cells are collected and frozen in a pellet, which is transferred to the urologist and thawed immediately prior to endourethral injection under endoscopic control. A recent review of stem cells for the treatment of urinary incontinence nicely describes the theory behind the use of stem cells for the treatment of urinary incontinence. (Staack \& Rodriguez 2011) Ideally, these autologous cells provide additional mucosal coaptation in order to restore resting urethral closing pressures. These studies are in their infancy and no data has been reported on women with refractory stress urinary incontinence, however this might provide a more effective means of endoscopic bulking without the use of collagen and other synthetic materials.

\section{Conclusion}

Traditional first-line therapies for stress urinary incontinence are not successful in all women and management of recurrent incontinence can be quite difficult. Options for these 
patients include conservative management, endoscopic management with periurethral bulking, a repeat sling procedure, spiral slings, the artificial urinary sphincter and adjustable continence therapy devices or new technologies such as autologous stem cell injection. Variable success rates for all of these methods have been reported in the literature depending on the length of follow up and the definition of cure.

\section{References}

Aboseif, S. R., E. I. Franke, et al. (2009). The adjustable continence therapy system for recurrent female stress urinary incontinence: 1-year results of the North America Clinical Study Group. J Urol 181(5): 2187-91.

Aboseif, S. R., P. Sassani, et al. (2011). Treatment of moderate to severe female stress urinary incontinence with the adjustable continence therapy (ACT) device after failed surgical repair. World J Urol 29(2): 249-53.

Bump, R. C. and P. A. Norton (1998). Epidemiology and natural history of pelvic floor dysfunction. Obstet Gynecol Clin North Am 25(4): 723-46.

Cammu, H., E. Van Den Abbeele, et al. (2009). Factors predictive of outcome in tension-free vaginal tape procedure for urinary stress incontinence in a teaching hospital. Int Urogynecol J Pelvic Floor Dysfunct 20(7): 775-80.

Chung, E., A. Navaratnam, et al. (2010). Can artificial urinary sphincter be an effective salvage option in women following failed anti-incontinence surgery? Int Urogynecol J 22(3): 363-6.

Costa, P., N. Mottet, et al. (2001). The use of an artificial urinary sphincter in women with type III incontinence and a negative Marshall test. J Urol 165(4): 1172-6.

Houwert, R. M., J. P. Roovers, et al. (2010). When to perform urodynamics before mid-urethral sling surgery for female stress urinary incontinence? Int Urogynecol J 21(3): 303-9.

Kocjancic, E., S. Crivellaro, et al. (2010). Adjustable continence therapy for severe intrinsic sphincter deficiency and recurrent female stress urinary incontinence: long-term experience. J Urol 184(3): 1017-21.

Lee, H. N., Y. S. Lee, et al. (2010). Transurethral injection of bulking agent for treatment of failed mid-urethral sling procedures. Int Urogynecol J 21(12): 1479-83.

Liapis, A., P. Bakas, et al. (2002). Burch colposuspension and tension-free vaginal tape in the management of stress urinary incontinence in women. Eur Urol 41(4): 469-73.

Light, J. K. and F. B. Scott (1985). Management of urinary incontinence in women with the artificial urinary sphincter. J Urol 134(3): 476-8.

Mingin, G. C., K. Youngren, et al. (2002). The rectus myofascial wrap in the management of urethral sphincter incompetence. BJU Int 90(6): 550-3.

Mitterberger, M., G. M. Pinggera, et al. (2008). Adult stem cell therapy of female stress urinary incontinence. Eur Urol 53(1): 169-75.

Mourtzinos, A., M. G. Maher, et al. (2008). Spiral sling salvage anti-incontinence surgery for women with refractory stress urinary incontinence: surgical outcome and satisfaction determined by patient-driven questionnaires. Urology 72(5): 1044-8; discussion 1048-50.

Nilsson, C. G., C. Falconer, et al. (2004). Seven-year follow-up of the tension-free vaginal tape procedure for treatment of urinary incontinence. Obstet Gynecol 104(6): 1259-62. 
Nilsson, C. G., N. Kuuva, et al. (2001). Long-term results of the tension-free vaginal tape (TVT) procedure for surgical treatment of female stress urinary incontinence. Int Urogynecol J Pelvic Floor Dysfunct 12 Suppl 2: S5-8.

Petrou, S. P. and I. Frank (2001). Complications and initial continence rates after a repeat pubovaginal sling procedure for recurrent stress urinary incontinence. J Urol 165(6 Pt 1): 1979-81.

Revaux, A., M. Roupret, et al. (2010). Is the implantation of an artificial urinary sphincter with a large cuff in women with severe urinary incontinence associated with worse perioperative complications and functional outcomes than usual? Int Urogynecol J.

Rodriguez, A. R., T. Hakky, et al. (2010). Salvage spiral sling techniques: alternatives to manage disabling recurrent urinary incontinence in females. J Urol 184(6): 2429-33.

Rodriguez, L. V. and S. Raz (2003). Prospective analysis of patients treated with a distal urethral polypropylene sling for symptoms of stress urinary incontinence: surgical outcome and satisfaction determined by patient driven questionnaires. J Urol 170(3): 857-63; discussion 863.

Roupret, M., V. Misrai, et al. (2010). Laparoscopic approach for artificial urinary sphincter implantation in women with intrinsic sphincter deficiency incontinence: a singlecentre preliminary experience. Eur Urol 57(3): 499-504.

Rutman, M. P., D. Y. Deng, et al. (2006). Spiral sling salvage anti-incontinence surgery in female patients with a nonfunctional urethra: technique and initial results. J Urol 175(5): 1794-8; discussion 1798-9.

Sebe, P., C. Doucet, et al. (2011). Intrasphincteric injections of autologous muscular cells in women with refractory stress urinary incontinence: a prospective study. Int Urogynecol J 22(2): 183-9.

Shamliyan, T. A., R. L. Kane, et al. (2008). Systematic review: randomized, controlled trials of nonsurgical treatments for urinary incontinence in women. Ann Intern Med 148(6): 459-73.

Staack, A. and L. V. Rodriguez (2011). Stem cells for the treatment of urinary incontinence. Curr Urol Rep 12(1): 41-6.

Stav, K., P. L. Dwyer, et al. (2010). Repeat synthetic mid urethral sling procedure for women with recurrent stress urinary incontinence. J Urol 183(1): 241-6.

Stav, K., P. L. Dwyer, et al. (2010). Risk factors of treatment failure of midurethral sling procedures for women with urinary stress incontinence. Int Urogynecol J 21(2): 149-55.

Thomas, K., S. N. Venn, et al. (2002). Outcome of the artificial urinary sphincter in female patients. J Urol 167(4): 1720-2.

Uebersax, J. S., J. F. Wyman, et al. (1995). Short forms to assess life quality and symptom distress for urinary incontinence in women: the Incontinence Impact Questionnaire and the Urogenital Distress Inventory. Continence Program for Women Research Group. Neurourol Urodyn 14(2): 131-9.

Vayleux, B., J. Rigaud, et al. (2011). Female urinary incontinence and artificial urinary sphincter: study of efficacy and risk factors for failure and complications. Eur Urol 59(6): 1048-53.

Walsh, C. A. and K. H. Moore (2010). Recurrent stress urinary incontinence after synthetic midurethral sling procedure. Obstet Gynecol 115(6): 1296-301.

Ward, K. L. and P. Hilton (2004). A prospective multicenter randomized trial of tension-free vaginal tape and colposuspension for primary urodynamic stress incontinence: two-year follow-up. Am J Obstet Gynecol 190(2): 324-31. 


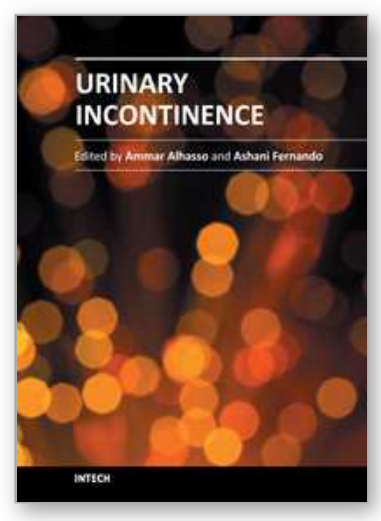

\author{
Urinary Incontinence \\ Edited by Mr. Ammar Alhasso
}

ISBN 978-953-51-0484-1

Hard cover, 324 pages

Publisher InTech

Published online 04, April, 2012

Published in print edition April, 2012

Management strategies are framed within a multidisciplinary team structure and as such a range of specialists ranging from psychologists, specialist nurses, gynaecologists and urologists author the chapters. There are some novel methods outlined by the authors with their clinical application and utility described in detail, along with exhaustive research on epidemiology, which is particularly relevant in planning for the future.

\title{
How to reference
}

In order to correctly reference this scholarly work, feel free to copy and paste the following:

Sara M. Lenherr and Arthur P. Mourtzinos (2012). Refractory Stress Urinary Incontinence, Urinary Incontinence, Mr. Ammar Alhasso (Ed.), ISBN: 978-953-51-0484-1, InTech, Available from: http://www.intechopen.com/books/urinary-incontinence/surgery-for-refractory-urinary-incontinence

\section{INTECH}

open science | open minds

\section{InTech Europe}

University Campus STeP Ri

Slavka Krautzeka 83/A

51000 Rijeka, Croatia

Phone: +385 (51) 770447

Fax: +385 (51) 686166

www.intechopen.com

\section{InTech China}

Unit 405, Office Block, Hotel Equatorial Shanghai

No.65, Yan An Road (West), Shanghai, 200040, China 中国上海市延安西路65号上海国际贵都大饭店办公楼405单元

Phone: +86-21-62489820

Fax: +86-21-62489821 
(C) 2012 The Author(s). Licensee IntechOpen. This is an open access article distributed under the terms of the Creative Commons Attribution 3.0 License, which permits unrestricted use, distribution, and reproduction in any medium, provided the original work is properly cited. 